\title{
Anthropopressure gradients and the population genetic structure of Apodemus agrarius
}

\author{
Tomasz Gortat • Robert Rutkowski • \\ Alicja Gryczyńska • Agnieszka Pieniążek • \\ Anna Kozakiewicz $\cdot$ Michał Kozakiewicz
}

Received: 18 March 2014/ Accepted: 15 December 2014/Published online: 21 December 2014

(c) The Author(s) 2014. This article is published with open access at Springerlink.com

\begin{abstract}
We have attempted to describe the genetic structure and variability of the striped field mouse population inhabiting 17 locations in and around Warsaw, Poland, within a gradient of anthropopressure and discuss the possible factors that could potentially form the observed pattern. Ecological characteristics of the striped field mouse prevent decreases in genetic variability within local urban populations. High population density, ability to cross environmental barriers and to use "green corridors" allows this species to maintain gene flow in fragmented urban landscape. However, genetic variability and gene flow were efficiently reduced in the central part of the city. The results indicated that the degree of human pressure, defined based on the level of vegetation cover, is a good indicator of isolation. In the studied striped field mouse population, genetic interactions among particular locations (local populations) are modified in comparison with populations inhabiting natural areas, by replacement of the
\end{abstract}

Electronic supplementary material The online version of this article (doi:10.1007/s10592-014-0690-0) contains supplementary material, which is available to authorized users.

T. Gortat · A. Gryczyńska · A. Pieniążek ·

M. Kozakiewicz $(\square)$

Department of Ecology, Faculty of Biology, Biological and

Chemical Research Centre, University of Warsaw, Żwirki i

Wigury 101, 02-089 Warsaw, Poland

e-mail: kozak@biol.uw.edu.pl

R. Rutkowski

Museum and Institute of Zoology Polish Academy of Science, Wilcza 64, 00-679 Warsaw, Poland

\section{A. Kozakiewicz}

Department of Hydrobiology, Faculty of Biology, Biological and Chemical Research Centre, University of Warsaw, Żwirki i Wigury 101, 02-089 Warsaw, Poland isolation-by-distance pattern of differentiation with the "isolation-by-infrastructure" pattern. As indicated by Bayesian analysis, the urban population from the right side of the Vistula river form common genetic cluster with exurban population located northward from the city, while the population from the left side of the river probably exchanges genes with neighbouring northern and southern ex-urban populations. However local populations at locations within the highest zone of anthropopressure are clearly isolated, and presently constitute separate genetic units.

Keywords Apodemus agrarius · Anthropopressure · Ecological barriers - Urban population - Genetic structure

\section{Introduction}

In general, urban populations of wild animals have been considered fragmented, with groups of individuals inhabiting patches of suitable habitat being more or less isolated, depending on the mobility of the species and its ability to cross environmental barriers. The process of fragmentation and isolation, followed by subsequent genetic drift and increased relatedness among individuals, has been confirmed not only in the case of animals of low mobility (e.g. Noël et al. 2007; Noël and Lapointe 2010; Mikulič and Pišút 2012; Munshi-South et al. 2013), but also for mobile "active colonizers" (Wandeler et al. 2003; Rasner et al. 2004; Evans et al. 2009). However, there are many other examples including small mammals (Mossman and Waser 2001; Gardner-Santana et al. 2009; Munshi-South and Kharchenko 2010), which suggest that genetic variability within an urban environment may not necessarily be decreased in comparison with ex-urban populations. These 
observations may be explained by an after-effect of ongoing immigration to urban areas, multiple sources of colonization and/or sufficiently large effective population sizes to maintain a high level of genetic variation within suitable habitat patches. However, it is also possible that heterogeneity of the urban environment allows a high level of genetic variability to be maintained in some areas (large suitable habitat patches connected with ex-urban areas), whereas in other areas that have been more drastically changed by man (heavily built-up sites containing small patches surrounded by busy roads and/or by large areas of unsuitable habitat), the level of genetic variability is clearly reduced. Unfortunately, few studies have examined the relationship between the level of habitat modification (anthropopressure) within cities and the level of genetic variability of urban populations (Rutkowski et al. 2005; Munshi-South 2012).

Less ambiguous results were obtained when the level of genetic structuring of urban populations was analyzed. Almost all studies underlined the much higher genetic differentiation among populations within urban areas compared to the natural environment (e.g. Desender et al. 2005; Gardner-Santana et al. 2009; Björklund et al. 2010; Delaney et al. 2010; Vangestel et al. 2011; Munshi-South et al. 2013; Unfried et al. 2013).

Some studies have also indicated that genetic drift is a much stronger factor shaping the population genetic structure of fragmented urban populations than mutation and gene flow (Wood and Pullin 2002; Noël et al. 2007; Munshi-South and Kharchenko 2010; Unfried et al. 2013). Since at least some of the studied species exhibit little genetic structure in natural areas (e.g. Munshi-South and Kharchenko 2010; Gortat et al. 2013), it appears that urbanization is a particularly potent factor affecting genetic differentiation compared to natural fragmentation of the environment.

There have been relatively few studies investigating the population genetics of city-dwelling rodents (e.g. Hirota et al. 2004; Gardner-Santana et al. 2009; Gortat et al. 2013), and knowledge of the factors that contribute to the distribution of genetic variability within urban populations of these animals is still fragmentary. Thus, this study was initiated to investigate how the highly specific environmental conditions in a big city influence the genetic structure and genetic variability of wild living animal species. For the reasons outlined below, Warsaw was selected as the model city and the striped field mouse (Apodemus agrarius), as the model species. The principal goal of the study was to, describe the genetic structure and variability of the urban mouse population taking into account the heterogeneity of habitat, expressed in the form of an anthropopressure gradient (from natural ex-urban sites located out of the city to the heavily transformed city center) and discuss the possible natural (Vistula river, geographic distance) and anthropogenic (city infrastructure) factors that could potentially form the observed pattern.

\section{Methods}

\section{Study species}

The striped field mouse occurs in many habitats including woodland edge, grasslands, cultivated fields, as well as green spaces in urban areas such as gardens and parks (Babińska-Werka and Garbarczyk, 1981; Gliwicz and Kryštufek 1999). Its ability to cross environmental barriers and use "green corridors" traversing distances as long as $1,000 \mathrm{~m}$ or even more, allows this species to invade green areas in fragmented suburban landscape (Liro and Szacki 1987). For this reason, it represents a very good model species for studies on the synurbization process. The first record of it in Warsaw is from the end of the nineteenth century (Wałecki 1881). In the 1920s, it was described as a frequent species in the city (Sumiński 1922), so the synurbization process of this species in Warsaw dates back almost 100 years. Since the 1970s it has become the dominant wild rodent species in city parks, reaching very high densities (Andrzejewski et al. 1978; Liro 1985).

\section{Study area and field methods}

There are several reasons why the city of Warsaw is a very good model for studying the effects of urban habitat heterogeneity on wild animal species. The city is large enough to contain habitats representing different degrees of anthropopressure (population of about 2 million people, area of $517 \mathrm{sq} \mathrm{km}$ ). It is located on both sides of the Vistula River, which may constitute a potential natural habitat barrier that could prevent gene flow what was found in some small mammal populations separated by rivers (Aars et al. 1998; Gerlach and Musolf 2000). Moreover, the two parts of the city located on right (east) and left (west) sides of the river differ with respect to the type of housing. On the right side green patches cover a relatively large area and form green belts extending into the city. Also, the riverside in this part of the city has retained a more natural character and is a potential ecological corridor for animals entering the city. In contrast, the left side of central Warsaw is densely built-up, covered by a well developed network of wide streets with heavy traffic and contains relatively small and isolated green areas-mainly wellmaintained parks. Thus, the left and right sides of Warsaw may be considered as two types of urban agglomeration, characterized by different spatial structures, located in close proximity to one another. 
Studies were carried out in and around the city of Warsaw (Fig. 1). The mouse populations were examined in 17 locations comprising green areas such as parks and gardens on both sides of the Vistula river, situated at various distances from the city center. The selected sites contained habitats representing different degrees of human pressure according to a five-degree scale, as proposed by Sudnik-Wójcikowska (1988), where 1 is the lowest and 5 the highest degree of human pressure. This scale is based on the dominant vegetation type and the intensity of direct and indirect human interference defined as the percentage of the area potentially covered by vegetation: zone 1 (Z1) - natural vegetation covering $100 \%$ of the area (corresponds to an ex-urban habitat); zone 2 (Z2) —almost natural vegetation covering $>95 \%$ of the area (not present within the study area); zone 3 (Z3)—semi-natural vegetation covering $\geq 95 \%$ of the area; zone 4 (Z4) - synanthropic vegetation covering $70-95 \%$ of the area; zone 5 (Z5) - synanthropic vegetation covering $<70 \%$ of the area. According to these criteria the degree of anthropopressure for each 1.5 by $1.5 \mathrm{~km}$ square covering the whole area of Warsaw has been evaluated (Sudnik-Wójcikowska
1988). The average daytime level of noise produced by city traffic (cars, buses, trams etc.) expressed in decibels (dB) was used as an additional, direct indicator of anthropopressure (VIEP 2013) (Fig. 1) that could act as important stress-producing factor and strongly prevent movements of animals. Since the correlation between the noise level in close vicinities to our study areas and the degrees of anthropopressure based on soils and vegetation types was very strong and positive $(\mathrm{r}=0.9841, P<0.001)$, we concluded that both indicators can be used in analysis concerning the anthropopressure level.

The degree of anthropopressure of each particular sampling site was the same as that of the square in which it was located. The distances between locations within the city ranged from 2 to approximately $20 \mathrm{~km}$, and the area of green spaces comprising the urban sites varied from about 27 ha to more than 600 ha. Four of the studied locations were situated outside the city, two to the north and two to the south, on opposite banks of the river. All of the non-urban (ex-urban) locations were exposed to the lowest degree of human pressure. The distance between the two most widely separated ex-urban locations was about $50 \mathrm{~km}$.
Fig. 1 Map of the study area. Z1 to Z5-different zones of anthropopressure. L1 to L9 and R10 to R17—sampling locations on the left (L) and the right (R) banks of the Vistula river, respectively. Dash dotted lines represent genetic clusters of local populations of the striped field mouse, indicated by BAPS

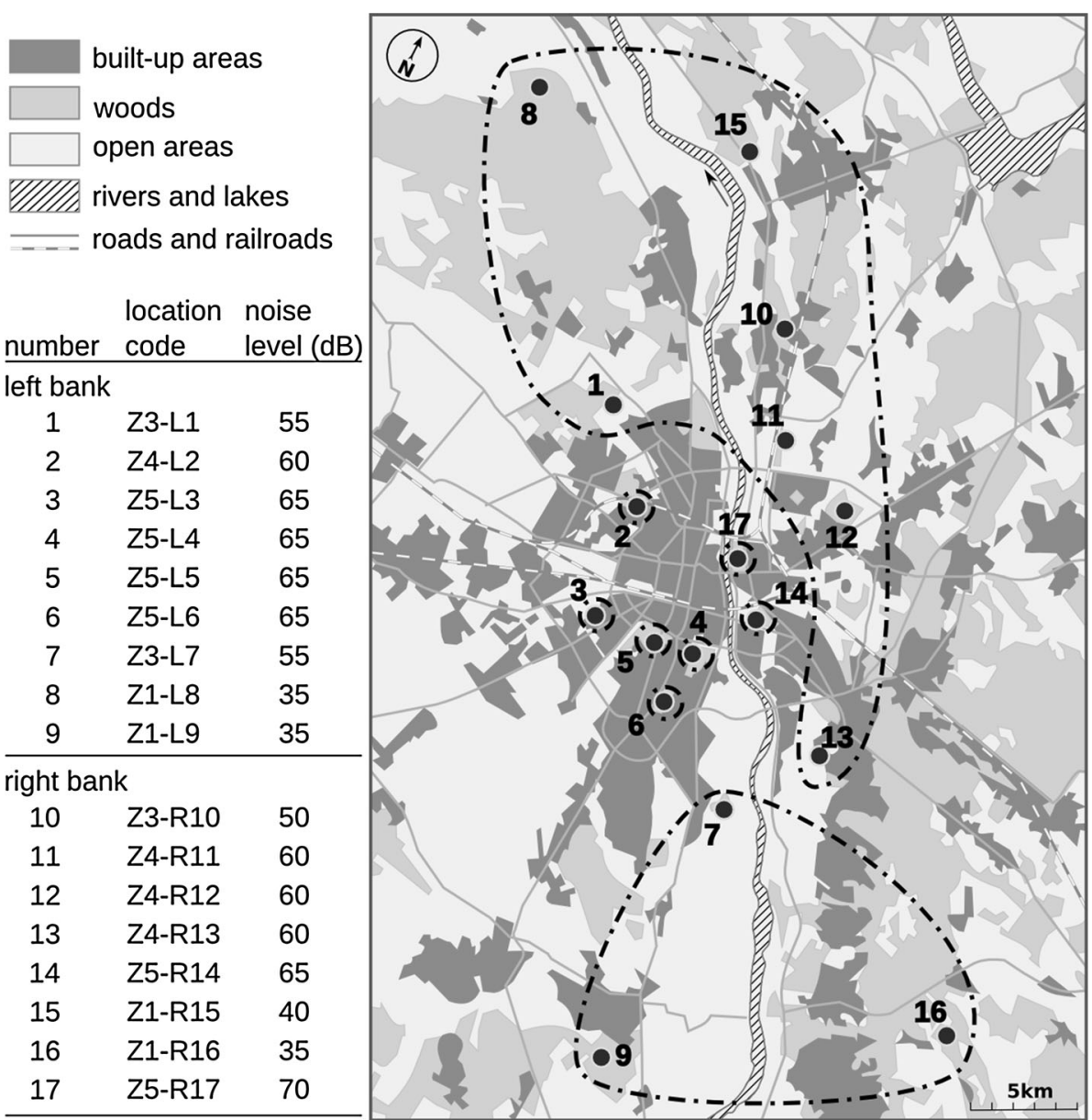


Trapping sessions were carried out in September 2010 and 2011 over 7 subsequent days at each location. At each site, a line was marked along which live traps for small mammals were placed. On each transect of approximately $600 \mathrm{~m}$ in length, 2 traps were located every $20 \mathrm{~m}$ (30 trapping points in total). The captured rodents were individually marked and an ear lobe sample was collected for genetic analysis before they were set free at the trapping site. Overall 502 mouse individuals were captured and genetic analyses were successfully performed for 490 of them (Table 1).

DNA isolation and amplification of microsatellite markers

Genomic DNA was extracted from mouse ear lobe samples using a Genomic Mini Isolation Kit (A\&A Biotechnology) according to the manufacturer's instructions.

A total of 17 previously described microsatellite loci were analyzed (Gockel et al. 1997; Makova et al. 1998; Ohnishi et al. 1998; Harr et al. 2000; Wu et al. 2008). All of the markers were amplified in three (I-III) independent multiplex PCRs (I: MSAA-5; GTTF9A, GACAD1A, GACAB3A; GTTC4A. II: TNF, GATAE10A, SFM3; CAA2A, SFM6; MSAf-22, GCATD7S. III: SFM14; SFM9; As-7, SFM1, SFM7). Each reaction contained $1 \mu$ of template DNA, $6.25 \mu \mathrm{l} 2 \times$ QIAGEN Multiplex PCR Master Mix (Qiagen), $1.25 \mu \mathrm{l} 5 \times$ Q-Solution (Qiagen), $1.25 \mu \mathrm{l}$ of
$10 \times$ primer mix (containing each primer at $2 \mu \mathrm{M}$ ), plus RNase-free water (Qiagen) to give a total volume of $12.5 \mu \mathrm{l}$. All reactions were carried out in a C-1000 Thermal Cycler (Bio-Rad) with the following conditions: $94{ }^{\circ} \mathrm{C}$ for $15 \mathrm{~min}$, followed by 30 cycles of $94^{\circ} \mathrm{C}$ for $30 \mathrm{~s}, 57^{\circ} \mathrm{C}$ for $3 \mathrm{~min}, 72{ }^{\circ} \mathrm{C}$ for $1 \mathrm{~min}$, and a final extension at $68^{\circ} \mathrm{C}$ for $15 \mathrm{~min}$.

The forward primers were labelled with one of the fluorescent Well Read labels (Sigma-Aldrich): Dye2, Dye3 or Dye4. Negative PCR controls were always included in each set of reactions. No amplification product was detected in any negative control after electrophoresis on an agarose gel or analysis in an automatic sequencer.

The precise size of the amplified fragments was measured using a CEQ8000 Beckman Coulter automatic sequencer. The data were analyzed using Beckman Coulter Fragment Analysis Software.

Statistical analysis

Initially we assessed the observed heterozygosity $\left(H_{\mathrm{O}}\right)$, unbiased expected heterozygosity $\left(H_{\mathrm{E}}\right)$ (Nei and Roychoudhury 1974) and performed a probability test for deviation from the Hardy-Weinberg equilibrium using Genepop on the Web version 4.0.10 (Raymond and Rousset 1995; Rousset 2008) for each locus at each of the 17 sampling sites. Significant heterozygote deficiency was

Table 1 Summary of mean genetic variability indices in 14 microsatellite loci of Apodemus agrarius from 17 sampling locations $(n=490)$

\begin{tabular}{|c|c|c|c|c|c|c|c|c|c|c|c|c|}
\hline River bank & $\mathrm{Z}$ & Location & $n$ & $A$ & $R$ & $\mathrm{Ne}$ & $A p$ & $P A R$ & $H_{\mathrm{O}}$ & $H_{\mathrm{E}}$ & $H W E$ & $F_{\text {IS }}$ \\
\hline $\mathrm{L}$ & 1 & Z1-L8 & 32 & 7.43 & 6.31 & 4.33 & 0.29 & 0.16 & 0.629 & 0.668 & $* * *$ & 0.073 \\
\hline $\mathrm{L}$ & 1 & Z1-L9 & 21 & 6.71 & 6.20 & 4.10 & 0.07 & 0.05 & 0.651 & 0.689 & $* *$ & $0.079 *$ \\
\hline $\mathrm{L}$ & 3 & Z3-L7 & 15 & 6.64 & 6.56 & 3.82 & 0.14 & 0.17 & 0.700 & 0.696 & ns & 0.029 \\
\hline $\mathrm{L}$ & 3 & Z3-L1 & 17 & 6.07 & 5.81 & 3.68 & 0.21 & 0.19 & 0.616 & 0.657 & $* * *$ & $0.094 *$ \\
\hline $\mathrm{L}$ & 4 & Z4-L2 & 41 & 6.07 & 4.98 & 3.26 & 0.14 & 0.08 & 0.609 & 0.626 & ns & 0.039 \\
\hline $\mathrm{L}$ & 5 & Z5-L3 & 21 & 6.00 & 5.55 & 3.66 & 0.07 & 0.22 & 0.656 & 0.668 & $\mathrm{~ns}$ & 0.041 \\
\hline $\mathrm{L}$ & 5 & Z5-L4 & 49 & 6.93 & 5.67 & 3.93 & 0.00 & 0.01 & 0.673 & 0.687 & $* *$ & 0.030 \\
\hline $\mathrm{L}$ & 5 & Z5-L5 & 53 & 6.07 & 4.91 & 3.51 & 0.00 & 0.03 & 0.618 & 0.636 & $* * *$ & 0.039 \\
\hline $\mathrm{L}$ & 5 & Z5-L6 & 19 & 5.29 & 4.88 & 3.04 & 0.00 & 0.00 & 0.586 & 0.583 & ns & 0.022 \\
\hline $\mathrm{R}$ & 1 & Z1-R15 & 25 & 6.79 & 5.85 & 3.61 & 0.14 & 0.10 & 0.644 & 0.644 & $\mathrm{~ns}$ & 0.020 \\
\hline $\mathrm{R}$ & 1 & Z1-R16 & 24 & 6.86 & 6.06 & 4.20 & 0.07 & 0.05 & 0.699 & 0.694 & ns & 0.014 \\
\hline $\mathrm{R}$ & 3 & Z3-R10 & 24 & 6.43 & 5.75 & 4.06 & 0.07 & 0.08 & 0.729 & 0.678 & ns & -0.054 \\
\hline $\mathrm{R}$ & 4 & Z4-R11 & 28 & 7.07 & 6.21 & 4.32 & 0.07 & 0.10 & 0.690 & 0.691 & ns & 0.020 \\
\hline $\mathrm{R}$ & 4 & Z4-R12 & 27 & 6.29 & 5.46 & 3.34 & 0.07 & 0.06 & 0.625 & 0.623 & ns & 0.016 \\
\hline $\mathrm{R}$ & 4 & Z4-R13 & 35 & 6.93 & 5.79 & 4.04 & 0.00 & 0.04 & 0.679 & 0.665 & ns & -0.006 \\
\hline $\mathrm{R}$ & 5 & Z5-R14 & 35 & 5.57 & 4.84 & 3.22 & 0.14 & 0.09 & 0.629 & 0.628 & ns & 0.013 \\
\hline $\mathrm{R}$ & 5 & Z5-R17 & 24 & 5.29 & 4.89 & 3.47 & 0.00 & 0.00 & 0.648 & 0.603 & ns & -0.054 \\
\hline
\end{tabular}

$\bar{L} R$ left/right side of the river, $Z$ zone of anthropopressure, $n$ number of individuals, $A$ allelic diversity, $R$ allelic richness, Ne effective number of alleles, $A p$ mean private alleles, $P A R$ private allelic richness, $H_{\mathrm{O}}$ observed heterozygosity, $H_{\mathrm{E}}$ expected heterozygosity, $H W E$ significance of $H W E$ exact test for heterozygote deficiency/excess (** $P<0.01, * * * P<0.001), F_{\text {IS }}$ inbreeding coefficient $(*$ values significant after Bonferroni correction, 4,760 randomization, adjusted $P$ value $=0.00021)$. Sampling site abbreviations are as in Fig. 1 
found in the case of the markers SFM3, SFM14 and As7 at the majority of the sampling sites $(9,15$ and 10 of the sites, respectively) (online Appendix A). It was assumed that such a regular pattern resulted from the presence of null alleles, so these three loci were excluded from further analysis. Therefore, we finally estimated the genetic variability and differentiation in the studied mouse population based on 14 microsatellite markers.

Genetic variability, estimated based on microsatellite polymorphism, was assessed at a few levels. Firstly, separately for each sampling site we determined allelic diversity $(A)$, mean number of private alleles $(A p)$, observed heterozygosity $\left(H_{\mathrm{O}}\right)$ and unbiased expected heterozygosity $\left(H_{\mathrm{E}}\right)$ (Nei and Roychoudhury 1974), using GenAlEx version 6.0 (Paekall and Smouse 2001). Allelic richness $(R)$ (Petit et al. 1998) was estimated using FSTAT version 2.9.3.2 (Goudet 2002), and private allelic richness (PAR), using HP-RARE (Kalinowski 2005). The inbreeding coefficient $\left(F_{\text {IS }}\right)$ was calculated for each sampling site and its significance was tested using the randomization procedure and Bonferroni correction for multiple comparisons. These analyses were performed using FSTAT.

Genotypic linkage disequilibrium between all pairs of loci, as well as the probability test for deviation from the Hardy-Weinberg equilibrium were evaluated using Genepop on the Web version 4.0.10 (Raymond and Rousset 1995; Rousset 2008). The analyses were then performed for each anthropopressure zone. The significance of differences between mean values of allelic richness (calculated across separate sampling sites within each anthropopressure zone), $F_{\mathrm{IS}}, F_{\mathrm{ST}}$, observed heterozygosity and relatedness (calculated using an estimator equivalent; Queller and Goodnight 1989) in anthropopressure zones were tested using the permutation procedure as implemented in FSTAT. Similar comparisons were also performed between the river banks. Genetic differentiation between sampling sites was estimated using $F_{\mathrm{ST}}$. Overall $F_{\text {ST }}$ (Weir and Cockerham 1984) for each anthropopressure zone and the river banks, as well as the pairwise $F_{\mathrm{ST}}$ among all sampling sites, were evaluated using FSTAT. The $95 \%$ confidence intervals for overall $F_{\mathrm{ST}}$ were also estimated with FSTAT. We also estimated contemporary gene flow among sampling sites: migration rates among pairs of localizations, as well as fraction of 'resident' individuals within each localization were calculated using BayesAss 3.0 (Wilson and Rannala 2003). We performed five independent runs, using different random number seeds and different number of iterations. The convergence among runs were analysed using Tracer 1.6 (Rambaut et al. 2014). The highest convergence was reached at 10,000,000 iterations. The mixing parameters were adjusted according to authors' recommendations (Wilson and Rannala 2003).
The Bayesian-based method implemented in BAPS (version 6.0; Corander and Marttinen 2006; Corander et al. $2008 \mathrm{a}, \mathrm{b})$ was used to analyze the spatial clustering of groups, followed by admixture analysis. Five replicates were run for every upper level of $K(7,14,21$ and 28). The number of iterations that were used to estimate the admixture coefficient for the individuals and the number of reference individuals from each location was 50. The number of iterations used to estimate the admixture for the reference individuals was set to 15 .

In order to determine (1) the relationship between the genetic distance and the geographic distance separating the local populations (separately for each bank of the river) and (2) the relationship between the genetic distance and the geographic distance separating groups of local populations inhabiting the same anthropopressure zones (the same degree of anthropopressure), linear regression and Pearson's product-moment correlation coefficient (r) were calculated, and the significance of the regression was evaluated by analysis of variance (ANOVA). The relationship between the genetic distance and geographic distance was calculated according to the method proposed by Rousset (1997) and based on $F_{\mathrm{ST}} /\left(1-F_{\mathrm{ST}}\right)$ index and natural logarithm of distance ( $\ln \mathrm{m}$ ). Differences between regression slopes were evaluated using the global linear model (GLM III type of sum square calculation, without contrasts). GLM was also used (1) to determine whether the relationships between genetic distance $\left[F_{\mathrm{ST}} /\left(1-F_{\mathrm{ST}}\right)\right]$ and geographic distance (ln $\mathrm{m}$ ) separating local mouse populations were significantly different on both banks of the river, and (2) to determine the relationship between the genetic distance $\left[F_{\mathrm{ST}} /\left(1-F_{\mathrm{ST}}\right)\right]$ of local populations and the degree of anthropopressure.

\section{Results}

All of the analyzed microsatellites were polymorphic, with 5-25 alleles per locus (online Appendix B). The mean number of alleles per locus $(A)$ in the sampling sites ranged from 5.29 to 7.43 . The highest $A$ values ( $>7$ alleles per locus) were observed in two sites, whereas values below 6.0 were found in only three locations in Z5. Allelic richness $(R)$ was the highest in Z3-L7. $R$ values exceeding 6.0 were also found in three sampling sites in $\mathrm{Z} 1$ and in one from Z4. Values of $R$ of below 5.0 were found in three sites from Z5 and one from Z4 (Table 1). Private alleles were found in 12 of the 17 analyzed locations. The highest mean number of private alleles was found on the left side of the river (Z1-L8 and Z3-L1). No private alleles were found in four of the six studied sites in $\mathrm{Z} 5$ and in one from $\mathrm{Z} 4$ on the right side of the river (Table 1 ). The observed heterozygosity $\left(H_{\mathrm{O}}\right)$ was the highest in two locations from $\mathrm{Z3}$ as 
well as in Z1-R16. The lowest value of $H_{\mathrm{O}}$ was found in Z5-L6 (Table 1). Of the 17 studied sampling sites, 5 were not in Hardy-Weinberg equilibrium $(H W E)$. Significant heterozygote deficiency was found exclusively in sites on the left side of the river. Among these sites, significant values of $F_{\text {IS }}$ were found only for Z1-L9 and Z3-L1 (Table 1).

Upon comparing genetic variability among sampling sites grouped according to anthropopressure zone, we found significantly lower allelic richness in Z5 $(R=5.13)$ than in Z1 or Z3 ( $R=6.01$ and 6.04 , respectively) (onesided test, 1,000 permutations, $P<0.01)$. Moreover, observed heterozygosity was significantly lower in Z5 $\left(H_{\mathrm{O}}=0.638\right)$ than in $\mathrm{Z3}\left(H_{\mathrm{O}}=0.687\right.$, one-sided test, 1,000 permutations, $P<0.05$ ). The relatedness coefficient calculated for Z5 (relat $=0.211$ ) was significantly higher than those for $\mathrm{Z} 1$ (relat $=0.096, \quad P<0.001), \quad \mathrm{Z} 3$ (relat $=0.104, \quad P<0.05)$ and $\mathrm{Z} 4 \quad$ (relat $=0.118$, $P<0.05)$. The values of $R$ and $H_{\mathrm{O}}$ were not significantly different between Z5 and Z4 $\left(R=5.61\right.$ and $\left.H_{\mathrm{O}}=0.648\right)$. Also, there was no statistically significant difference between $\mathrm{Z1}, \mathrm{Z} 3$ and $\mathrm{Z} 4$ when pairwise comparisons were made for $R, H_{\mathrm{O}}$ and relat. The value of $F_{\mathrm{IS}}$ ranged from 0.012 (Z3) to $0.047(\mathrm{Z} 1)$ and did not differ significantly among the all anthropopressure zones.

The level of genetic variability was similar on both sides of the river $\left(R=5.652\right.$ and $5.608 ; H_{\mathrm{O}}=0.636$ and 0.667 ; relat $=0.158$ and 0.125 , for the left and right sides, respectively), but $F_{\text {IS }}$ was significantly higher (one-sided test, 1000 permutations, $P<0.001)$ on the left side $\left(F_{\mathrm{IS}}=0.046\right)$ than on the right $\left(F_{\mathrm{IS}}=-0.030\right)$.

The overall genetic differentiation in the analyzed striped field mouse population was moderate $\left(F_{\mathrm{ST}}=\right.$ $0.085,95 \%$ CI $0.075-0.097$ ). Despite the fact that sampling sites in Z1 were located on opposite sides of the city or different sides of the river (Fig. 1), the overall genetic differentiation in this group of sites was the smallest $\left(F_{\mathrm{ST}}=0.053,95 \%\right.$ CI $\left.0.037-0.069\right)$, but it was not significantly different from the overall genetic differentiation in Z3 $\left(F_{\mathrm{ST}}=0.055,95 \%\right.$ CI $\left.0.043-0.067\right)$ and Z4 $\left(F_{\mathrm{ST}}=0.064,95 \%\right.$ CI $\left.0.045-0.086\right)$. The overall genetic differentiation in Z5 ( $F_{\mathrm{ST}}=0.120,95 \%$ CI $\left.0.099-0.142\right)$ was significantly higher than in all of the other zones (onesided test, 1,000 permutations, $P<0.05$ ). There was no significant overall genetic differentiation between $\mathrm{Z3}$ and Z4.

Pairwise genetic differentiation ranged from 0.026 to $0.181\left(F_{\mathrm{ST}}\right)$ (Table 2). The highest value was found between individual sampling sites in Z5, located on different banks of the Vistula River. The lowest differentiation was found between Z3-L7 and Z1-L9 (locations in bordering zones on the left side of the river, south of the city center) and Z4-R11 and Z4-R12 (directly bordering locations on the right side of the river.)

For almost all sites, estimated fraction of migrants was very low and 'residents' clearly dominated (67-92\%, online Appendix C). We did not find clear evidence for asymmetric pattern of gene flow, besides location Z4R12, which seems to be a source of immigrants for ex-urban and adjacent urban localizations. In general, the fraction of residents increased towards the city centre: while in $\mathrm{Z} 1$ and $\mathrm{Z} 3$ fraction of residents does not exceed $68 \%$, in all sites from Z5 the fraction was much higher (81-92\%, online Appendix C).

The relationship between genetic distance and geographic distance (for all sites independent of their location in relation to the river, i.e. left or right bank) calculated in groups of local populations inhabiting the same zone of human pressure was positive, but not statistically significant. However, the genetic distance was significantly dependent on the degree of anthropopressure (GLM: $\mathrm{F}=9.89, P<0.001)$. The highest values of genetic distance were found in locations with the highest degree of anthropopressure and values of this index declined in spite of the increase in distance (Fig. 2).

On both banks of the Vistula River, the genetic distance decreased with increasing geographic distance, and on the left bank this relationship was statistically significant $(\mathrm{r}=-0.4196$, ANOVA: $\mathrm{F}=7.260, P<0.01)$, while on the right side it did not differ significantly from zero $(\mathrm{r}=-0.1459$, ANOVA: $\mathrm{F}=0.570, P>0.46)$. In addition, the relationship between genetic and geographic distance was significantly different on both banks of the river (GLM, $\mathrm{F}=6.893, P<0.01$ ) (Fig. 3).

BAPS assigned all individuals to nine genetic clusters with a probability of 0.997 . The first cluster (green patches, Fig. 4) was found north of the city center and on the right side of the river in Z1-Z4, except site Z1-R16, which was assigned to another cluster (beige patches) together with two other locations south of the city center. Moreover, BAPS divided the mice from sites in Z5 (plus Z4-L2) into seven separate clusters (Figs. 1, 4).

\section{Discussion}

Genetic variability: urban versus ex-urban populations

The results obtained showed that the level of genetic variability is not clearly reduced in urban populations in comparison with ex-urban areas, indicating that only the most heavily modified zones of the city exhibit a significant decrease in the number of microsatellite alleles and increased relatedness among individuals. A similar pattern 
Table 2 Genetic differentiation $\left(F_{\mathrm{ST}}\right)$ among 17 sampling locations from Warsaw city center and neighboring ex-urban areas

\begin{tabular}{|c|c|c|c|c|c|c|c|c|c|c|c|c|c|c|c|c|c|}
\hline & $\begin{array}{l}\text { Z1- } \\
\text { L8 }\end{array}$ & $\begin{array}{l}\text { Z1- } \\
\text { L9 }\end{array}$ & $\begin{array}{l}\text { Z3- } \\
\text { L7 }\end{array}$ & $\begin{array}{l}\text { Z3- } \\
\text { L1 }\end{array}$ & $\begin{array}{l}\mathrm{Z} 4- \\
\mathrm{L} 2\end{array}$ & $\begin{array}{l}\text { Z5- } \\
\text { L3 }\end{array}$ & $\begin{array}{l}\text { Z5- } \\
\text { L4 }\end{array}$ & $\begin{array}{l}\text { Z5- } \\
\text { L5 }\end{array}$ & $\begin{array}{l}\text { Z5- } \\
\text { L6 }\end{array}$ & $\begin{array}{l}\text { Z1- } \\
\text { R15 }\end{array}$ & $\begin{array}{l}\text { Z1- } \\
\text { R16 }\end{array}$ & $\begin{array}{l}\text { Z3- } \\
\text { R10 }\end{array}$ & $\begin{array}{l}\text { Z4- } \\
\text { R11 }\end{array}$ & $\begin{array}{l}\text { Z4- } \\
\text { R12 }\end{array}$ & $\begin{array}{l}\text { Z4- } \\
\text { R13 }\end{array}$ & $\begin{array}{l}\text { Z5- } \\
\text { R14 }\end{array}$ & $\begin{array}{l}\text { Z5- } \\
\text { R17 }\end{array}$ \\
\hline $\begin{array}{r}\text { Z1- } \\
\text { L8 }\end{array}$ & & 0.054 & 0.074 & 0.053 & 0.061 & 0.065 & 0.049 & 0.123 & 0.103 & 0.032 & 0.066 & 0.042 & 0.032 & 0.049 & 0.048 & 0.088 & 0.064 \\
\hline $\begin{array}{r}\text { Z1- } \\
\text { L9 }\end{array}$ & & & 0.026 & 0.056 & 0.076 & 0.073 & 0.060 & 0.074 & 0.094 & 0.048 & 0.060 & 0.043 & 0.049 & 0.077 & 0.044 & 0.106 & 0.104 \\
\hline $\begin{array}{r}\text { Z3- } \\
\text { L7 }\end{array}$ & & & & 0.069 & 0.084 & 0.069 & 0.043 & 0.074 & 0.106 & 0.059 & 0.072 & 0.055 & 0.051 & 0.089 & 0.073 & 0.099 & 0.121 \\
\hline $\begin{array}{r}\mathrm{Z3}- \\
\mathrm{L} 1\end{array}$ & & & & & 0.087 & 0.065 & 0.078 & 0.104 & 0.105 & 0.034 & 0.079 & 0.047 & 0.055 & 0.081 & 0.057 & 0.118 & 0.120 \\
\hline $\begin{array}{r}\mathrm{Z} 4- \\
\mathrm{L} 2\end{array}$ & & & & & & 0.102 & 0.095 & 0.141 & 0.148 & 0.070 & 0.108 & 0.075 & 0.068 & 0.103 & 0.077 & 0.115 & 0.099 \\
\hline $\begin{array}{r}\text { Z5- } \\
\text { L3 }\end{array}$ & & & & & & & 0.065 & 0.102 & 0.096 & 0.055 & 0.103 & 0.060 & 0.050 & 0.080 & 0.076 & 0.115 & 0.143 \\
\hline $\begin{array}{r}\mathrm{Z} 5- \\
\text { L4 }\end{array}$ & & & & & & & & 0.092 & 0.104 & 0.057 & 0.094 & 0.065 & 0.051 & 0.075 & 0.075 & 0.100 & 0.120 \\
\hline $\begin{array}{r}\text { Z5- } \\
\text { L5 }\end{array}$ & & & & & & & & & 0.148 & 0.108 & 0.123 & 0.098 & 0.121 & 0.155 & 0.107 & 0.154 & 0.181 \\
\hline $\begin{array}{r}\text { Z5- } \\
\text { L6 }\end{array}$ & & & & & & & & & & 0.075 & 0.109 & 0.103 & 0.080 & 0.075 & 0.081 & 0.136 & 0.164 \\
\hline $\begin{array}{l}\mathrm{Z} 1- \\
\mathrm{R} 15\end{array}$ & & & & & & & & & & & 0.058 & 0.037 & 0.030 & 0.034 & 0.030 & 0.077 & 0.088 \\
\hline $\begin{array}{l}\text { Z1- } \\
\text { R16 }\end{array}$ & & & & & & & & & & & & 0.069 & 0.057 & 0.081 & 0.043 & 0.089 & 0.071 \\
\hline $\begin{array}{l}\text { Z3- } \\
\text { R10 }\end{array}$ & & & & & & & & & & & & & 0.040 & 0.062 & 0.044 & 0.100 & 0.125 \\
\hline $\begin{array}{l}\text { Z4- } \\
\text { R11 }\end{array}$ & & & & & & & & & & & & & & 0.030 & 0.031 & 0.070 & 0.073 \\
\hline $\begin{array}{l}\text { Z4- } \\
\text { R12 }\end{array}$ & & & & & & & & & & & & & & & 0.053 & 0.098 & 0.091 \\
\hline $\begin{array}{l}\text { Z4- } \\
\text { R13 }\end{array}$ & & & & & & & & & & & & & & & & 0.081 & 0.081 \\
\hline $\begin{array}{l}\text { Z5- } \\
\text { R14 }\end{array}$ & & & & & & & & & & & & & & & & & 0.111 \\
\hline
\end{tabular}

All values of (except one shown in bold) were significant after Bonferroni correction (2,720 randomizations, adjusted $P$ value $=0.004)$

has also been observed in other rodents (Gardner-Santana et al. 2009; Munshi-South and Kharchenko 2010). In theory, the genetic variability of urban populations should be decreased due to habitat fragmentation and the low effective size of populations inhabiting limited patches of suitable habitat (Evans et al. 2010). However, these two factors seem to have limited effects on urban rodents. Probably, the high population densities in small habitat fragments prevent the loss of genetic variability. Very high densities have been reported for local populations of the striped field mouse inhabiting city parks in Warsaw (Andrzejewski et al. 1978; Liro 1985; Izdebska 1997). Similarly, the white-footed mouse was found at much higher densities in fragmented habitats-including the urban environmentthan in undisturbed habitats (e.g. Nupp and Swihart 1996; Rytwinski and Fahrig 2007).
The presence of green spaces within the urban environment could be another factor limiting the decrease in genetic variability of city-dwelling species (Munshi-South 2012). Hence, we assume that in the case of the striped field mouse, their high population densities, high abundance plus the presence of green corridors for gene flow, permit the retention of quite high levels of genetic variability in urban populations as a whole. Moreover, it was suggested that the species could be relatively insensitive to presence of environmental barriers, such roads and streets (Rhim et al. 2003; Gortat et al. 2014). However, heavily built-up areas, combined with a scarcity of "green corridors" act as a very effective barrier to gene flow. Thus, we observed a significant decrease in genetic variability in the most transformed area of the city: Z5. This effect is the clearest in the case of the number of microsatellite alleles. 


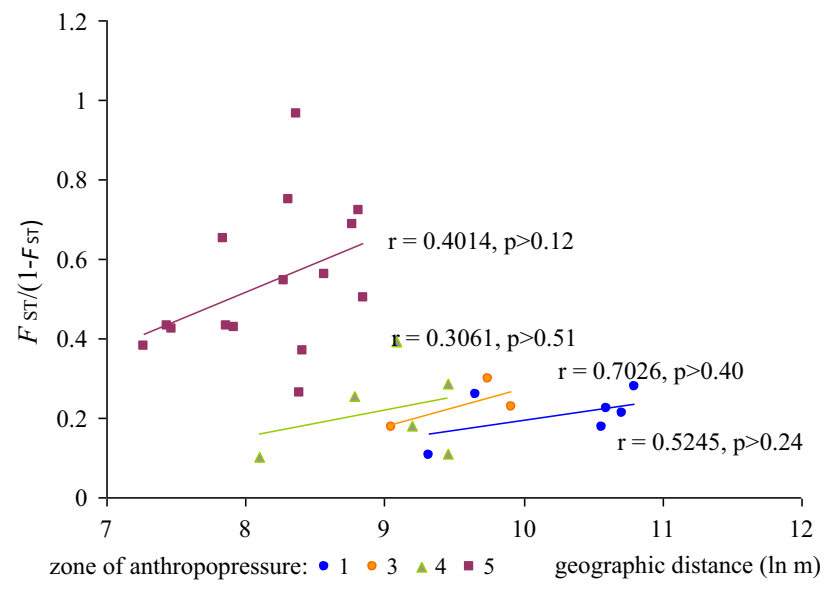

Fig. 2 The relationship between genetic distance $\left[F_{\mathrm{ST}} /\left(1-F_{\mathrm{ST}}\right)\right]$ and natural logarithm of geographic distance $(\mathrm{ln} \mathrm{m})$ in groups of local populations inhabiting the same anthropopressure zones

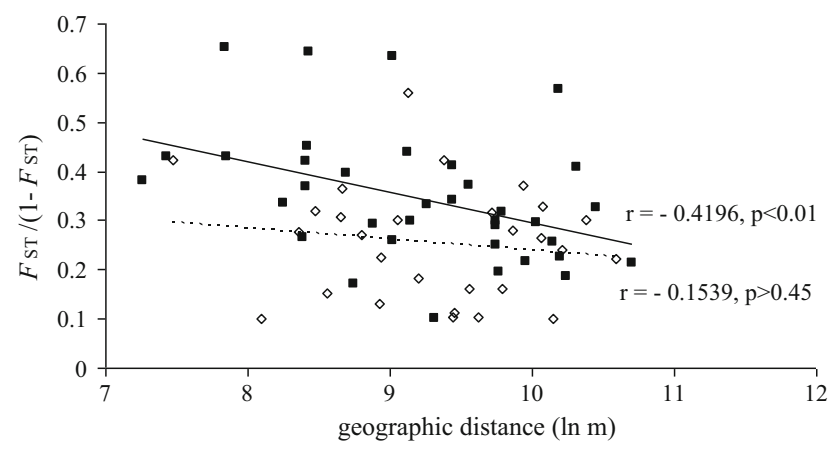

Fig. 3 The relationship between genetic distance $\left[F_{\mathrm{ST}} /\left(1-F_{\mathrm{ST}}\right)\right]$ and natural logarithm of geographic distance $(\mathrm{ln} \mathrm{m})$ on the left (black points and solid line) and right (white points and dotted line) banks of the Vistula river

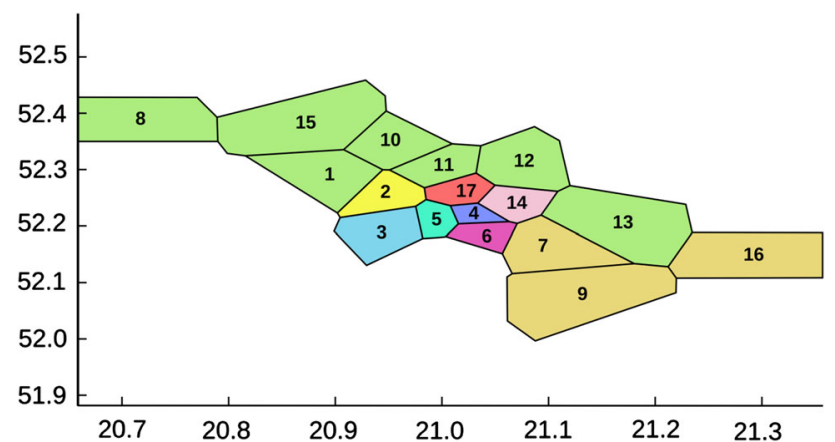

Fig. 4 Nine genetic clusters inferred using the spatial model in BAPS 6.0. Axes represent spatial X, Y coordinates of the proportional membership of individuals for each of the nine inferred clusters. Numbers from 1 to 17 denote a particular location (see Fig. 1)

When genetic drift in isolated populations reduces genetic variability at neutral loci, the effect could be more easily detected in the number of alleles than in the heterozygosity level (Nei et al. 1975). Indeed, we usually did not detect private alleles in locations from $\mathrm{Z5}$. The isolation of local populations from highest anthropopressure zone is also confirmed by significantly higher values of the relatedness coefficient compared with those calculated for other sites. Thus, our results show that local populations from central parts of Warsaw, despite the high densities of individuals observed in some cases, suffer from decreased genetic variability, mainly due to isolation. The movement of individuals during the seasonal emigration is probably largely restrained by the surrounding unsuitable habitat, leading to increased relatedness. These effects are most clearly expressed in sites located on the left bank of the Vistula River in the central zone, as this part of Warsaw is more heavily built-up and devoid of green areas.

Genetic differentiation within anthropopressure zones

We detected significant differences in the level of differentiation only for comparisons with Z5. This result supports the effective isolation of populations inhabiting the center of the city, but not those within Z3 and Z4. According to Schtickzelle and Baguette (2003) sharp ecotonal boundaries (e.g. between green park areas and streets or a heavily built-up housing estate) can cause individuals to cluster inside the patch, thus producing so-called "fence effect". Our results indicate that in the case of Z5, a "fence effect" could be an explanation for the observed distribution of genetic variability. On the other hand, genetic differentiation within Z3 and Z4 was very similar to that among ex-urban sampling locations. We suggest that the presence of the appropriate level of vegetation cover has ensured gene flow, thus preventing an increase in genetic differentiation.

\section{Genetic differentiation among sampling sites}

Genetic differentiation among sampling sites within an urban environment usually loses the isolation-by-distance pattern observed in the same species within a natural environment (Wood and Pullin 2002; Noël et al. 2007; Munshi-South and Kharchenko 2010; Gortat et al. 2013). This observation is supported by the results of our study. The relationship between geographic and genetic distances, calculated separately for groups of local populations inhabiting different anthropopressure zones, clearly shows that for subpopulations separated by similar geographic distances, those situated in the zones of higher anthropopressure display higher genetic differentiation. MunshiSouth (2012) found that the pattern of isolation-by-effective distance (IED), calculated based on the percentage of tree canopy cover, was the best model explaining the intensity of gene flow among urban populations of the 
white-footed mouse. Our analysis can support the validity of this pattern, because the level of genetic differentiation in the striped field mouse was partially explained by the degree of anthropopressure, defined based on vegetation characteristics (Sudnik-Wójcikowska 1988). Moreover, on the left bank of the Vistula River a negative correlation between geographical and genetic distance was observed, because the highest $F_{\mathrm{ST}}$ values were found for pairs of local populations located in close proximity but separated by the dense buildings and busy streets in the city center.

Water bodies, such as lakes (Kozakiewicz et al. 2009; Gortat et al. 2010; Taylor and Hoffman 2010) and rivers (Aars et al. 1998; Gerlach and Musolf 2000) can act as effective natural barriers preventing gene flow. However, we found that genetic differentiation between pairs of exurban sampling sites located on opposite sides of the river was small, suggesting the existence of gene flow. At the same time, pairs of sampling sites located across the river but close to the city center, differed significantly from each other. This means that the river acts as a more effective barrier within the city than beyond its limits. The higher effectiveness of the barrier within the city center might be due to the highly developed left bank of the river in this part of the city, which precludes the access of animals to the riverside. Moreover, the presence of islands in the river both north and south of the city, giving better connectivity across the river beyond the city limits, could produce the observed pattern of differentiation.

\section{Population genetic structure}

The Bayesian method applied to analyze genetic structure suggested higher genetic homogeneity on the right side of the Vistula River. The undisturbed river bank in this part of the city probably constitutes an important ecological corridor for mammals. In addition, as discussed above, local populations on the right side of the river are less isolated from each other than those on the left side. Indeed, Wahlund effects seem to be weaker in the "right-side" population than in the "left-side". This is suggested by the significantly lower $F_{\text {IS }}$ value, indicating no heterozygote deficiency due to population subdivision on the right side of the Vistula.

The BAPS analysis also suggested that ex-urban populations of the striped field mouse are separated by the city. The "northern cluster" penetrates Warsaw much further within the urbanized landscape than the "southern cluster", especially on the right side of the river (Fig. 1). This may indicate that this part of Warsaw is better connected by gene flow with the northern than with the southern ex-urban populations. Two sites from $\mathrm{Z} 5$ are differentiated from the other locations on the right bank due to isolation and subsequent genetic drift, but their genetic relationship with the "right-side locations" is still visible, as indicated by $F_{\mathrm{ST}}$ values. On the left side of the Vistula, the reach of both "northern", and "southern" clusters appears to be much shallower. Therefore, we suggest that on the left side of the river ex-urban locations are connected by the gene flow only with neighbouring urban sites while central locations experienced rapid differentiation due to isolation and genetic drift, and presently constitute separate genetic units, as indicated by BAPS. It is also possible, that presently observed genetic distinctiveness might be an effect of admixture events between northern and southern genotypes in a central contact zone. Anyway, the patterns of genetic differentiation on the left and right sides of the river are different. (Fig. 1).

The analysis of fractions of 'resident' and 'migrating' individuals within each localization calculated using BayesAss 3.0 (Wilson and Rannala 2003) is fully consistent with the results of BAPS analysis and indicates that isolation of local populations increases towards city centre. Moreover, it also showed that recently on the right side of the river the location Z4R12 plays a crucial role in shaping the genetic structure of almost whole population by sending reasonably large groups of migrants to other adjacent localities. Since this location also shows a high gene flow to location Z1L9 belonging to another genetic cluster and located on the opposite bank of the river, it could be suggested that the striped field mouse is able within one or, at least, a couple of generations to reach even distant locations and cross the river. On the left side of the river there is no such a source locality as Z4R12, probably because of stronger isolation of local populations by city infrastructure, especially located close to the city centre. Therefore, it seems that anthropopressure explains the gene flow between locations not only as specific variable within patches, but mainly as one of the variables that makes habitat between patches (city infrastructure) more or less permeable. It can be therefore concluded that in the studied striped field mouse population, genetic interactions among particular local populations are modified in comparison with populations inhabiting natural areas, by replacement of the isolation-by-distance pattern of differentiation with the "isolation-by-infrastructure" pattern.

Acknowledgments This study was financed by the National Science Centre (Grant No. N N304 169539). We are grateful to J. Gittins for English correction and useful critical comments and to $\mathrm{dr}$ Miłosława Sokół for her help with applying statistical methods. Trapping and handling procedures were approved by the First Warsaw Local Ethics Committee for Animal Experimentation (Permission No. 21/2010).

Open Access This article is distributed under the terms of the Creative Commons Attribution License which permits any use, distribution, and reproduction in any medium, provided the original author(s) and the source are credited. 


\section{References}

Aars J, Ims RA, Liu H-P, Mulvey M, Smith MH (1998) Bank voles in linear habitats show restricted gene flow as revealed by mitochondrial DNA (mtDNA). Mol Ecol 7:1383-1389

Andrzejewski R, Babińska-Werka J, Gliwicz J, Goszczyński J (1978) Synurbization processes in population of Apodemus agrarius. I. Characteristics of populations in urbanization gradient. Acta Theriol 23:341-358

Babińska-Werka J, Garbarczyk H (1981) Animal component of the diet of the striped field mouse under urban conditions. Acta Theriol 26:301-318

Björklund M, Ruiz I, Senar J (2010) Genetic differentiation in the urban habitat: the great tits (Parus major) of the parks of Barcelona city. Biol J Linn Soc 99:9-19

Corander J, Marttinen P (2006) Bayesian identification of admixture events using multi-locus molecular markers. Mol Ecol 15:2833-2843

Corander J, Sirén J, Arjas E (2008a) Bayesian spatial modelling of genetic population structure. Comput Stat 23:111-129

Corander J, Marttinen P, Sirén J, Tang J (2008b) Enhanced Bayesian modelling in BAPS software for learning genetic structures of populations. BMC Bioinform 9:539

Delaney KS, Riley SPD, Fisher RN (2010) A rapid, strong and convergent genetic response to urban habitat fragmentation in four divergent and widespread vertebrates. PLoS One 5(9): e12767

Desender K, Small E, Gaublomme E, Verdyck P (2005) Rural-urban gradients and the population genetic structure of woodland ground beetles. Conserv Genet 6:51-62

Evans KL, Gaston KJ, Frantz AC, Simeoni M, Sharp SP, McGowan A, Dawson DA, Walasz K, Partecke J, Burke T, Hatchwell BJ (2009) Independent colonization of multiple urban centres by a formerly forest specialist bird species. Proc R Soc B 276:2403-2410

Evans KL, Hatchwell BJ, Parnell M, Gaston KJ (2010) A conceptual framework for the colonisation of urban areas: the blackbird Turdus merula as a case study. Biol Rev Camb Philos Soc 85:643-667

Gardner-Santana LC, Norris DE, Fornadel CM, Hinson ER, Klein SL, Glass GE (2009) Commensal ecology, urban landscapes, and their influence on the genetic characteristics of city-dwelling Norway rats (Rattus norvegicus). Mol Ecol 18:2766-2778

Gerlach G, Musolf K (2000) Fragmentation of landscape as a cause for genetic subdivision in bank voles. Conserv Biol 14:1066-1074

Gliwicz J, Kryštufek B (1999) Apodemus agrarius. In: Mitchell-Jones AJ, Amori G, Bogdanowicz W, Kryštufek B, Reijnders PJH, Spitzenberger F, Stubbe M, Thissen JBM, Vohralík V, Zima J (eds) The Atlas of European mammals. Academic Press, London

Gockel J, Harr B, Schlötterer C, Arnold W, Gerlach G, Tautz D (1997) Isolation and characterization of microsatellite loci from Apodemus flavicollis (Rodentia, Muridae) and Myodes glareolus (Rodentia, Cricetidae). Mol Ecol 6:597-599

Gortat T, Gryczyńska-Siemiątkowska A, Rutkowski R, Kozakiewicz A, Mikoszewski A, Kozakiewicz M (2010) Landscape pattern and genetic structure of a yellow-necked mouse Apodemus flavicollis population in north-eastern Poland. Acta Theriol 55:109-121

Gortat T, Rutkowski R, Gryczyńska-Siemiątkowska A, Kozakiewicz A, Kozakiewicz M (2013) Genetic structure in urban and rural populations of Apodemus agrarius in Poland. Mamm Biol 78:171-177

Gortat T, Barkowska M, Gryczyńska-Siemiątkowska A, Pieniążek A, Kozakiewicz A, Kozakiewicz M (2014) The effects of urbanization-small mammal communities in a gradient of human pressure in Warsaw city, Poland. Pol J Ecol 62(1):177-186
Goudet J (2002) FSTAT V2.9.3.2, a program to estimate and test gene diversities and fixation indices. http://www2.unil.ch/popgen/ softwares/fstat.htm

Harr B, Musolf K, Gerlach G (2000) Characterization and isolation of DNA microsatellite primers in wood mice (Apodemus sylvaticus, Rodentia). Mol Ecol 9:1664-1665

Hirota T, Hirohata T, Mashima H, Satoh T, Obara Y (2004) Population structure of the large Japanese field mouse, Apodemus speciosus (Rodentia: Muridae), in suburban landscape, based on mitochondrial D-loop sequences. Mol Ecol 13:3275-3282

Izdebska B (1997) Qualitative and quantitative investigations of small mammal fauna in Bydgoszcz area. Studia Przyr 13:35-48 (in Polish)

Kalinowski ST (2005) A computer program for performing rarefaction on measures of alleli diversity. Mol Ecol Notes 5:187-189

Kozakiewicz M, Gortat T, Panagiotopoulou H, Gryczyńska-Siemiątkowska A, Rutkowski R, Kozakiewicz A, Abramowicz K (2009) The spatial genetic structure of bank vole (Myodes glareolus) and the yellow-necked mouse (Apodemus flavicollis) populations: the effect of distance and habitat barriers. Anim Biol 59:169-187

Liro A (1985) Variation in weights of body and internal organs in the field mouse in a gradient of urban habitats. Acta Theriol 30:359-377

Liro A, Szacki J (1987) Movements of field mice Apodemus agrarius (Pallas) in a suburban mosaic of habitats. Oecologia 74:438-440

Makova KD, Patton JC, Krysanov EYU, Chesser RK, Baker RJ (1998) Microsatellite markers in wood mouse and striped field mouse (genus Apodemus). Mol Ecol 7:247-249

Mikulič P, Pišút P (2012) Genetic structure of the marsh frog (Phelophylax ridibundus) populations in urban landscape. Eur $\mathbf{J}$ Wild Res 58:833-845

Mossman C, Waser P (2001) Effects of habitat fragmentation on population genetic structure in the white-footed Mouse (Peromyscus leucopus). Can J Zool 79:285-295

Munshi-South J (2012) Urban landscape genetics: canopy cover predicts gene flow between white-footed mouse (Peromyscus leucopus) populations in New York city. Mol Ecol 21: $1360-1378$

Munshi-South J, Kharchenko K (2010) Rapid, pervasive genetic differentiation of urban white-footed mouse (Peromyscus leucopus) populations in New York city. Mol Ecol 19:4242-4254

Munshi-South J, Zak Y, Pehek E (2013) Conservation genetics of extremely isolated urban populations of the northern dusky salamander (Desmognathus fuscus) in New York city. Peer J, 1:e64. http://dx.doi.org/10.7717/peerj.64

Nei M, Roychoudhury AK (1974) Sampling variances of heterozygosity and genetic distance. Genetics 76:379-390

Nei M, Maruyama T, Chakraborty R (1975) The bottleneck effect and genetic variability in populations. Evolution 29:1-10

Noël S, Lapointe F-J (2010) Urban conservation genetics: study of a terrestrial salamander in the city. Biol Conserv 143:2823-2831

Noël S, Ouellet M, Galois P, Lapontaine F-J (2007) Impact of urban fragmentation on the genetic structure of the eastern red-backed salamander. Conserv Genet 8:599-606

Nupp TE, Swihart RK (1996) Effect of forest patch area on population attributes of white-footed mice (Peromyscus leucopus) in fragmented landscapes. Can J Zool 74:467-472

Ohnishi N, Ishibashi Y, Saitoh T, Abe S, Yoshida MC (1998) Polymorphic microsatellite DNA markers in the Japanese wood mouse Apodemus argenteus. Mol Ecol 7:1431-1432

Paekall R, Smouse PE (2001) GenAlEx V5: genetic analysis in excel. Population genetic software for teaching and research. Australian National University, Canberra. http://www.anu.ed.au/BoZo/ GenAlEx/ 
Petit RJ, El Mousadik A, Pons O (1998) Identifying populations for conservation on the basis of genetic markers. Conserv Biol 12:844-855

Queller DC, Goodnight KF (1989) Estimating relatedness using genetic markers. Evolution 43:258-275

Rambaut A, Suchard MA, Xie D, Drummond AJ (2014) Tracer v1.6, available from http://beast.bio.ed.ac.uk/Tracer

Rasner CA, Yeh P, Eggert LS, Hunt KE, Woodruff DS, Price TD (2004) Genetic and morphological evolution following a founder event in the dark-eyed junco, Junco hyemalis thurberi. Mol Ecol. 13:671-681

Raymond M, Rousset F (1995) GENEPOP (version 1.2): population genetics software for exact tests and ecumenicism. J Hered $86: 248-249$

Rhim SJ, Lee CB, Hur WH, Park YS, Choi SY, Piao R, Lee WS (2003) Influence of roads on small rodents population in fragmented forest areas, South Korea. J For Res 14(2):155-158

Rousset F (1997) Genetic differentiation and estimation of gene flow from F- statistics under isolation by distance. Genetics 145:1219-1228

Rousset F (2008) Genepop'007: a complete reimplementation of the Genepop software for Windows and Linux. Mol Ecol Res 8:103-106

Rutkowski R, Rejt Ł, Gryczyńska-Siemiątkowska A, Jagołkowska P (2005) Urbanization gradient and genetic variability of birdsexample of Kestrels in Warsaw. Berkut 14:130-136

Rytwinski T, Fahrig L (2007) Effect of road density on abundance of white-footed mice. Landsc Ecol 22:1501-1512

Schtickzelle N, Baguette M (2003) Behavioural responses to habitat patch boundaries restrict dispersal and generate emigrationpatch area relationships in fragmented landscapes. J Anim Ecol 72:533-545

Sudnik-Wójcikowska B (1988) Flora synanthropization and anthropopressure zones in a large urban agglomeration (exemplified by Warsaw). Flora 180:259-265
Sumiński SM (1922) Fauna Warszawy. Ziemia 12:328-335 (In Polish)

Taylor ZS, Hoffman SMG (2010) Mitochondrial DNA genetic structure transcends natural boundaries in Great Lakes populations of woodland deer mice (Peromyscus maniculatus gracilis). Can J Zool 88:404-415

Unfried TM, Huuser L, Marzluff JM (2013) Effects of urbanization on Song Sparrow (Melospiza melodia) population connectivity. Conserv Genet 14(1):41-53. doi:10.1007/s10592-012-0422-2

Vangestel C, Mergeay J, Dawson DA, Vandomme V, Lens L (2011) Spatial heterogenity in genetic relatedness among house sparrows along an urban-rural gradient as revealed by individualbased analysis. Mol Ecol 20:4643-4653

VIEP (2013) The State of the Environment in Mazowieckie Voivodship in 2012. Voivodship Inspectorate of Environmental Protection, Warsaw, p 173 (in polish)

Wałecki A (1881) Fauna zwierząt ssących Warszawy i jej stosunek do fauny całego kraju. Pamiętnik Fizjograficzny 1:268-291 (in polish)

Wandeler P, Funk M, Largiader R, Gloor S, Breitenmoser U (2003) The city-fox phenomenon: genetic consequences of a recent colonization of urban habitat. Mol Ecol 12:647-656

Weir BS, Cockerham CC (1984) Estimating F-statistics for the analysis of population structure. Evolution 38:1358-1370

Wilson GA, Rannala B (2003) Bayesian inference of recent migration rates using multilocus genotypes. Genetics 163:1177-1191

Wood BC, Pullin AS (2002) Persistence of species in a fragmented urban landscape: the importance of dispersal ability and habitat availability for grassland butterflies. Biodivs Conserv 11: $1451-1468$

Wu H, Zhan X-J, Yan L, Liu S-Y, Li M, Hu J-Ch, Wei F-W (2008) Isolation and characterization of fourteen microsatellite loci for striped field mouse (Apodemus agrarius). Conserv Genet 9: 1691-1693 